\title{
Dopamine Modulates Excitability of Spiny Neurons in the Avian Basal Ganglia
}

\author{
Long Ding ${ }^{2}$ and David J. Perkel ${ }^{1}$ \\ ${ }^{1}$ Departments of Zoology and Otolaryngology, University of Washington, Seattle, Washington 98195-6115, and \\ 2Department of Neuroscience, University of Pennsylvania, Philadelphia, Pennsylvania 19104
}

\begin{abstract}
The neural substrate of vocal learning in songbirds is an accessible system for studying motor learning and motor control in vertebrates. In the so-called song system, the anterior forebrain pathway (AFP), which is essential for song learning, resembles the mammalian basal ganglia-thalamocortical loop in its macroscopic organization, neuronal intrinsic properties, and microcircuitry. Area $X$, the first station in the AFP, and the surrounding lobus parolfactorius (LPO), are both parts of the avian basal ganglia. Like their mammalian counterparts, they receive dense dopaminergic innervation from the midbrain, but the physiological functions of this projection remain unclear. In this study, we investigated the effect of dopamine (DA) on excitability of spiny neurons in area $X$ and LPO. We recorded from neurons in brain slices of adult zebra finches and Bengalese finches, using whole-cell and perforated-patch recording techniques in
\end{abstract}

With easily measurable, stereotyped singing behaviors and discrete underlying neural components, the avian song system is a good model for studies of motor learning in vertebrates. In the song system (see Fig. 1A), the anterior forebrain pathway (AFP) is essential for song learning but not for song production (Bottjer et al., 1984; Sohrabji et al., 1990; Scharff and Nottebohm, 1991; Brainard and Doupe, 2000). This pathway begins with the projection from the premotor nucleus $\mathrm{HVc}$ (used as the proper name) to area $\mathrm{X}$, a part of the avian basal ganglia specialized for song learning.

Comparative studies have shown striking similarities between avian and mammalian basal ganglia in their topographic organization, synaptic connectivity, cytoarchitecture, and neurochemistry (Vates and Nottebohm, 1995; Bottjer and Johnson, 1997; Reiner et al., 1998; Luo et al., 2001). In particular, spiny neurons in the avian basal ganglia closely resemble the neostriatal medium spiny projection neurons in mammals in their morphology and intrinsic properties (Farries and Perkel, 2000). Both avian and mammalian basal ganglia receive dense dopaminergic innervation from midbrain nuclei (Lewis et al., 1981; Bottjer, 1993; Soha et

Received Dec. 19, 2001; revised March 18, 2002; accepted April 4, 2002.

This work was supported by grants to D.J.P. from National Institutes of Health (NIH) (R01-MH56646) and the National Science Foundation (IBN0196104) and by NIH/National Institute on Deafness and Other Communication Disorders P30 Core Grant DC04661. D.J.P. is an affiliate of the Virginia Merrill Bloedel Hearing Research Center. We thank Michael Farries for valuable discussions and technical support. We thank Michele Solis for valuable comments on this manuscript. We thank the reviewers for their constructive suggestions.

Correspondence should be addressed to David J. Perkel, Departments of Zoology and Otolaryngology, University of Washington, Box 356515, 1959 Northeast Pacific Street, Seattle, WA 98195-6115. E-mail: perkel@u.washington.edu.

Copyright (C) 2002 Society for Neuroscience $0270-6474 / 02 / 225210-09 \$ 15.00 / 0$ current-clamp configuration. We found that DA modulates excitability in spiny neurons; activation of D1- and D2-like DA receptors enhances and reduces excitability, respectively. These effects are similar to those observed in the mammalian neostriatum, with the main difference being that D1-like DA receptor activation enhances excitability in avian spiny neurons at hyperpolarized states. Our findings also indicate that some spiny neurons express both receptor types and suggest that receptor colocalization in the entire population can account for the spectrum of DA actions. The diversity of DA actions enables the DA system to fine-tune the dynamics of the song system and allows flexible control over song learning and production.

Key words: dopamine; basal ganglia; songbird; excitability; song learning; neuromodulation al., 1996) and express D1- and D2-like dopamine (DA) receptors (for review, see Missale et al., 1998; Durstewitz et al., 1999).

In mammals, dopaminergic inputs to the basal ganglia are important for motor control and learning (Graybiel et al., 1994; Schultz, 1998). In non-songbirds, administration of dopaminergic compounds induces stereotyped pecking, alteration in locomotor activities, sedation (Nistico and Stephenson, 1979; Sanberg and Mark, 1983; Yanai et al., 1995), and affects learning behaviors (McDougall et al., 1987). The neural loci and cellular mechanisms of these effects are still unclear, because there has been only one report (Matsushima et al., 2001) to our knowledge on the physiological actions of DA in the avian basal ganglia. Although the role of DA in song behavior is not known, extensive behavioral, physiological, and anatomical studies on the song system make it an attractive model for elucidating the role of DA in motor learning and control in vertebrates.

In this study, we examined the effect of DA on intrinsic properties of spiny neurons in area $\mathrm{X}$ and the lobus parolfactorius (LPO) in brain slice preparations of zebra finch and Bengalese finch. As in mammals, DA modulated the excitability of avian spiny neurons via activation of both D1- and D2-like DA receptors. D1-like DA receptor activation consistently increased excitability, and D2-like DA receptor activation reduced excitability. The main effect of DA was inhibitory, as in the mammalian neostriatum. Thus DA can affect information processing in the avian basal ganglia and potentially modulate singing behavior in songbirds.

\section{MATERIALS AND METHODS}

Slice preparation. Thirty-seven adult male zebra finches (Taeniopygia guttata) and four Bengalese finches (Lonchura striata var. domestica) were obtained from two suppliers. Birds were kept in groups of five or fewer 
on a 13:11 hr light/dark cycle. Slicing procedures were as described by Farries and Perkel (2000) and were approved by the Institutional Animal Care and Use Committees at the University of Pennsylvania and the University of Washington. Briefly, birds were anesthetized using isoflurane and decapitated. The brain was quickly removed and immersed in ice-cold artificial CSF (ACSF) containing (in mM): $119 \mathrm{NaCl}, 2.5 \mathrm{KCl}$, $1.3 \mathrm{MgSO}_{4}, 2.5 \mathrm{CaCl}_{2}, 1 \mathrm{NaH}_{2} \mathrm{PO}_{4}, 16.2 \mathrm{NaHCO}_{3}, 11 \mathrm{D}$-glucose, and 10 HEPES, osmolarity 290-310 mOsm. Slices (300-350 $\mu \mathrm{m}$ thick) were cut parasagittally or coronally with a vibrating microtome in ice-cold ACSF and then transferred to a storage chamber containing ACSF heated to $30-35^{\circ} \mathrm{C}$. The storage chamber was allowed to cool to room temperature after slicing was completed. In both the storage and recording ACSF, HEPES was replaced with equiosmolar $\mathrm{NaHCO}_{3}$. All solutions were bubbled with a $95 \% \mathrm{O}_{2}$ and $5 \% \mathrm{CO}_{2}$ mixture.

Electrophysiological recording. Recordings started $>30$ min after slices were collected in the storage chamber. For recording, a slice was submerged in a small chamber perfused (flow rate, $2-3 \mathrm{ml} / \mathrm{min}$ ) with HEPES-free ACSF at $22-28^{\circ} \mathrm{C}$. When trans-illuminated, area $\mathrm{X}$ is visually identifiable as a dark region in the paleostriatal complex ventral to the lamina medullaris dorsalis. Neurons in area X and in LPO around area $\mathrm{X}$ were recorded using either the "blind" whole-cell technique (Blanton et al., 1989) or the gramicidin-perforated-patch technique (Rhee et al., 1994). Glass pipettes were pulled to have a tip of $<2 \mu \mathrm{m}$ in diameter (Micropipette Puller P-97, Sutters Instrument Co., Novato, CA).

Whole-cell recordings. Pipettes were filled with internal solutions containing (in mM): $120 \mathrm{~K}$ methylsulfate, $10 \mathrm{HEPES}, 2$ EGTA, $8 \mathrm{NaCl}, 2$ ATP, 0.3 GTP, and $2 \mathrm{MgCl}_{2}$, pH 7.25-7.35, osmolarity 265-300 mOsm. In many cases, $0.5 \%$ neurobiotin or biocytin (Vector Laboratories, Burlingame, CA) was also added to the pipette solution for histological reconstruction of the cells recorded. The electrode resistance ranged from 6 to $10 \mathrm{M} \Omega$. Signals were first amplified with an Axoclamp 2B (Axon Instruments, Foster City, CA) and then low-pass filtered $(3 \mathrm{kHz})$ and further amplified with a Brownlee Model 410 amplifier (Brownlee Precision, Santa Clara, CA). The filtered signals were digitized at $6 \mathrm{kHz}$ with a National Instruments (Austin, TX) digitizing board and stored in a PC using a custom data acquisition program written in LabView (National Instruments) by M. A. Farries (University of Pennsylvania) and D. J. Perkel. Drugs used in the experiments included S(-)-SKF38393 hydrochloride, 6-cyano-7-nitroquinoxaline-2,3-dione (CNQX) (Research Biochemicals, Natick, MA), atropine, picrotoxin, $(R)(+)-$ SCH-23390 hydrochloride, (-)-quinpirole hydrochloride, and DA (Sigma, St. Louis, MO), D(-)-2-amino-5-phosphonopentanoic acid (D-APV) and $(S)-(-)$ sulpiride (Tocris, Ballwin, MO) and CGP35348 (generous gift from Novartis, Basel, Switzerland). All drugs were bath applied.

Perforated-patch recordings. Gramicidin (Sigma) stock solutions were made fresh in dimethylsulfoxide at a concentration of $0.1-0.2 \mathrm{mg} / \mathrm{ml}$. The tip of the pipette was filled with internal solution containing (in $\mathrm{mM}$ ): $134 \mathrm{~K}$ methylsulfate, $10 \mathrm{HEPES}, 0.5$ EGTA, $8 \mathrm{NaCl}$, and $2 \mathrm{MgCl}_{2}, \mathrm{pH}$ $7.25-7.35$, osmolarity $246-265 \mathrm{mOsm}$. The rest of the tip was filled with the same internal solution supplemented with gramicidin stock solutions to a final concentration of $0.1-0.2 \mu \mathrm{g} / \mathrm{ml}$. The electrode resistance ranged from 6 to $10 \mathrm{M} \Omega$. The same recording system was used as for the whole-cell configuration. Once a gigaohm seal was achieved, the recorded potential usually stabilized in 5-10 min, whereas the series resistance stabilized at $\sim 200 \mathrm{M} \Omega$ in $20-40 \mathrm{~min}$. Experiments proceeded as in the whole-cell configuration after the membrane potential and series resistance reached a steady level.

Experiment protocols and analysis. We monitored excitability by counting the number of action potentials (APs) evoked by a suprathreshold current pulse injection. The intensity of the current pulse was predetermined for each experiment to ensure that the number of spikes elicited was in the middle of its firing range before any drug application. In some cases, we injected current pulses of several intensity levels to sample the full firing range of a cell. The duration of a current pulse was $0.5 \mathrm{sec}$. The interval between consecutive pulses ranged from 5 to $45 \mathrm{sec}$ and was regular throughout each experiment. We took the average number of spikes evoked by 10 current pulses ( 5 pulses if the interval was $>30 \mathrm{sec}$ ) before drug application as the measure of "pre-drug" excitability. We used the average number of spikes evoked by 10 pulses 6 min after the onset of drug application (or 5 pulses around the end of drug application if the interval was $>30 \mathrm{sec}$ ), as the "during-drug" excitability. The percentage change in spikes was calculated as (during-drug - pre-drug)/ pre-drug, in percentage.

The steady-state membrane voltage deflection in response to a $20 \mathrm{pA}$ hyperpolarizing pulse was used to monitor the resting input resistance of a cell. In some cases, we calculated the ratio between responses to 80 and $20 \mathrm{pA}$ hyperpolarizing pulses (ratio of inward rectification) to sample possible changes in the inward rectifying conductance. We also measured several electrophysiological parameters of the voltage responses to depolarizing current pulses. The initial ramp slope in response to a suprathreshold current pulse was measured as the slope of the regression line of all sample points in a time window of $20-50 \mathrm{msec}$ at $50-70 \mathrm{msec}$ after the onset of each pulse before the occurrence of the first action potential. The onset of an AP was defined as the averaged times of the maxima of the second and third derivatives of a waveform. The membrane potential at the onset of an AP was taken as the spike threshold. The voltage difference between the spike threshold and the peak of an AP was measured as the spike amplitude. The voltage difference between the spike threshold and the trough immediately after an AP was measured as the amplitude of the afterhyperpolarization (AHP). The duration of an AHP was defined as its width at half-height of the trough. For each suprathreshold current pulse, the measurements from all APs evoked were averaged. The time difference between the onset of the current pulse and the peak of the first AP elicited was measured as the "latency to first spike."

Possibly because of a washout effect associated with whole-cell recording, many cells showed a continuous decrease in evoked firing before any drug application. Often their evoked firing was reduced significantly within $5 \mathrm{~min}$ after the initial gigaohm seal was broken. These cells were excluded from analysis. Also excluded were cells with unstable membrane potential or input resistance before drug applications. Statistical results were obtained using internal functions in Prism 2.01/3.0 (GraphPad Software, San Diego, CA).

Histological procedures. In cases in which neurobiotin or biocytin was added to the pipette solution, slices were fixed in paraformaldehyde (4\% in PBS) overnight at $4^{\circ} \mathrm{C}$ and transferred to a sucrose solution (30\% sucrose in PBS) for cryoprotection. After at least $10 \mathrm{hr}$ of immersion in the sucrose solution at $4^{\circ} \mathrm{C}$, slices were sectioned to $50 \mu \mathrm{m}$ thickness with a freezing microtome. Resectioned slices were processed with an avidinbiotin horseradish peroxidase complex kit, Vector ABC Elite Kit, followed by a reaction with the Vector VIP peroxidase substrate kit (Vector Laboratories). Labeled neurons were inspected with $40 \times$ and $100 \times$ objectives to verify that they had the characteristic morphological features of spiny neurons as described previously by Farries and Perkel (2000; 2002).

\section{RESULTS}

We recorded from spiny neurons in area $\mathrm{X}$ and the surrounding LPO region in current-clamp configuration. Spiny neurons were identified by their distinct intrinsic properties as described previously (Farries and Perkel, 2000). The typical voltage response of a spiny neuron to current injection is shown in Figure $1 B$. It demonstrates two characteristic electrophysiological features: a slow ramping depolarization before action potentials in response to a suprathreshold current injection and a fast inward rectification revealed by hyperpolarizing current injections. Some of the spiny neurons with these features were also recovered histologically $(n=19)$. They all had small cell bodies and spiny dendrites. A montage of photomicrograph images from the cell in Figure $1 B$ is shown in Figure $1 C$.

In songbirds, the spiny neurons in area $X$ and LPO have indistinguishable intrinsic properties (Farries and Perkel, 2002). Area X and LPO both receive dense dopaminergic innervation from the ventral area of Tsai (AVT) (Lewis et al., 1981). We observed that DA modulates excitability of spiny neurons in both area $\mathrm{X}$ and LPO. Because there was no statistically significant difference between area X and LPO spiny neurons in their response to DA, we have combined data from both structures.

\section{DA has complex actions on spiny neuron excitability}

Bath application of DA had variable effects on excitability in spiny neurons. In the majority of cells, DA reduced the number of evoked spikes (Fig. $2 A, B$ ). In this example, before DA application, each $0.5 \mathrm{sec}$ current pulse elicited an average of three spikes. 
Figure 1. The song system and an example of a spiny neuron in area X. $A$, A simplified diagram of the oscine song system. The song system consists of three major pathways. The nucleus interfacialis (NIf) provides the auditory inputs to the song system. The motor pathway starts with nucleus $\mathrm{HVc}$ (used as a proper name). HVc projects to the robust nucleus of the archistriatum $(R A)$, which innervates several brainstem nuclei for control of respiration and vocalization. The AFP starts with the projection from $\mathrm{HVc}$ to area $\mathrm{X}$, a paleostriatal nucleus surrounded by lobus parolfactorius $(L P O)$. Area $\mathrm{X}$ projects to the medial portion of the dorsolateral anterior thalamic nucleus $(D L M)$, which sends its output to the lateral portion of the magnocellular nucleus of the anterior neostriatum $(I M A N)$, which projects to RA. The AFP is essential for normal song learning but is not required for song production in adults. Area X and LPO receive dense dopaminergic inputs from the ventral area of Tsai $(A V T)$. The gray area represents the paleostriatal complex. $B$, Voltage responses of a spiny neuron in area $\mathrm{X}$ to current pulse injec-

tions. Current pulse intensities: $+0.22,+0.15,+0.12,-0.02,-0.04,-0.12$, and $-0.14 \mathrm{nA}$. $C$, A montage of photomicrograph images of the neuron in $B$. The images were taken at different focal planes and locations. They were then aligned, using the soma and processes of the neuron as landmarks, onto a uniformly gray background. The cell has spiny dendrites and small soma (diameter $\sim 10 \mu \mathrm{m}$ ). Scale bar, $20 \mu \mathrm{m}$.

In the presence of DA, the cell did not spike during the same depolarizing stimulus. This decrease in firing was reversible, and the recovery time depended on the duration of DA application (compare the time courses of two sequential DA applications in Fig. $2 A$ ). In some cells, DA reversibly enhanced cell excitability (Fig. $2 C, D$ ). The distribution of the effects of DA on excitability of spiny neurons is shown in Figure $2 E(n=15)$. The percentage change in the number of evoked spikes varied widely, between -87.1 and $+72 \%$ with a mean of $-15.7 \%$ and SD of $38.06 \%$. There were no distinguishable clusters; the distribution of percentage changes in firing seemed continuous, with a bias toward negative values.

To examine whether the effect of DA depends on the baseline evoked firing activity, we monitored the cell response to current pulses at three intensity levels, which evoked from 2 to 10 spikes per pulse $(n=9)$. In each cell, DA changed the firing activity in the same direction for all three current intensity levels, indicating that the opposite effects of DA do not depend on the baseline evoked firing activity.

Given the complexity in the response of spiny neurons to DA, we hypothesized that the action of DA is the result of activation of multiple DA receptor types. In non-songbirds, LPO shows intense labeling for D1- and D2-like DA receptors in autoradiography binding studies [pigeon, Richfield et al. (1987); Dietl and Palacios (1988); chick, Schnabel and Braun (1996); Stewart et al. (1996)]. In songbirds, LPO and area X both show expression of D1-like DA receptors (Casto and Ball, 1994). The distribution of D2-like DA receptors in area X has not been reported. In the mammalian basal ganglia, activation of different receptor types by DA can trigger different signal cascades, leading to multiple, sometimes opposing, effects on membrane properties or synaptic transmission (for review, see Nicola et al., 2000). We thus examined the effects of activation of D1- and D2-like DA receptors and whether these effects could account for the spectrum of DA actions.

\section{The D1-like DA receptor agonist SKF-38393 enhances excitability in spiny neurons}

Application of the D1-like DA receptor agonist SKF-38393 reversibly enhanced evoked firing in some spiny neurons $(10 \mu \mathrm{M})$
(Fig. 3). The percentage change in evoked firing with SKF-38393 varied between -8.06 and $+362 \%$, with a mean of $+66.4 \%$ and SD of $96.5 \%(n=14)$ (see Fig. 9). SKF-38393 did not affect excitability in four cells (three in LPO, one in area X), possibly reflecting the relatively lower density of D1-like DA receptors in LPO than in area X (Casto and Ball, 1994). The enhancing effect of SKF-38393 is voltage dependent (Fig. 4), with a larger increase in evoked firing observed in cells at more depolarized states.

To test whether the effect of SKF-38393 was D1-like receptor specific, we applied the D1-like DA receptor antagonist $\mathrm{SCH}$ $23390(10-20 \mu \mathrm{M}) 2-4$ min before and throughout SKF-38393 (10 $\mu \mathrm{M})$ application. SCH-23390 had no effect of its own on evoked firing, but blocked the SKF-38393-induced enhancement of evoked firing (Fig. $5 A, B$ ). In the four neurons tested, the percentage change in evoked firing by SKF-38393 in the presence of SCH-23390 ranged from -16.7 to $+10 \%$, with a mean of $-3.87 \%$ and SD of $11.5 \%$ (see Fig. 9).

To test whether activation of D1-like DA receptors can account for the enhancing effect of DA, we applied DA and SKF-38393 sequentially in four neurons. In one cell, both SKF-38393 and DA increased the number of evoked spikes (Fig. 5A,C), suggesting that DA enhanced cell excitability via activation of D1-like DA receptors. Indeed, when DA was subsequently applied in the presence of SCH-23390 $(10 \mu \mathrm{M})$ in the same cell, it no longer increased spiking activity. Rather, by blocking activation of the D1-like DA receptors, SCH-23390 unmasked a significant DA-induced reduction in firing of more than $60 \%$ (Figs. 5D, 9), suggesting that other DA receptors were present in this cell and that DA reduces excitability via activation of non-D1-like DA receptors. The functional existence of non-D1-like DA receptors was further supported by data from the other three cells, two in area X and one in LPO, in which DA decreased evoked spike activity whereas SKF38393 increased cell excitability or had no effect. Taken together, these results indicate that activation of D1-like DA receptors can account for the enhancing effect of DA; D1-like DA receptors and other DA receptors are present in the same cells; and DA reduces excitability by activating non-D1-like DA receptors. 

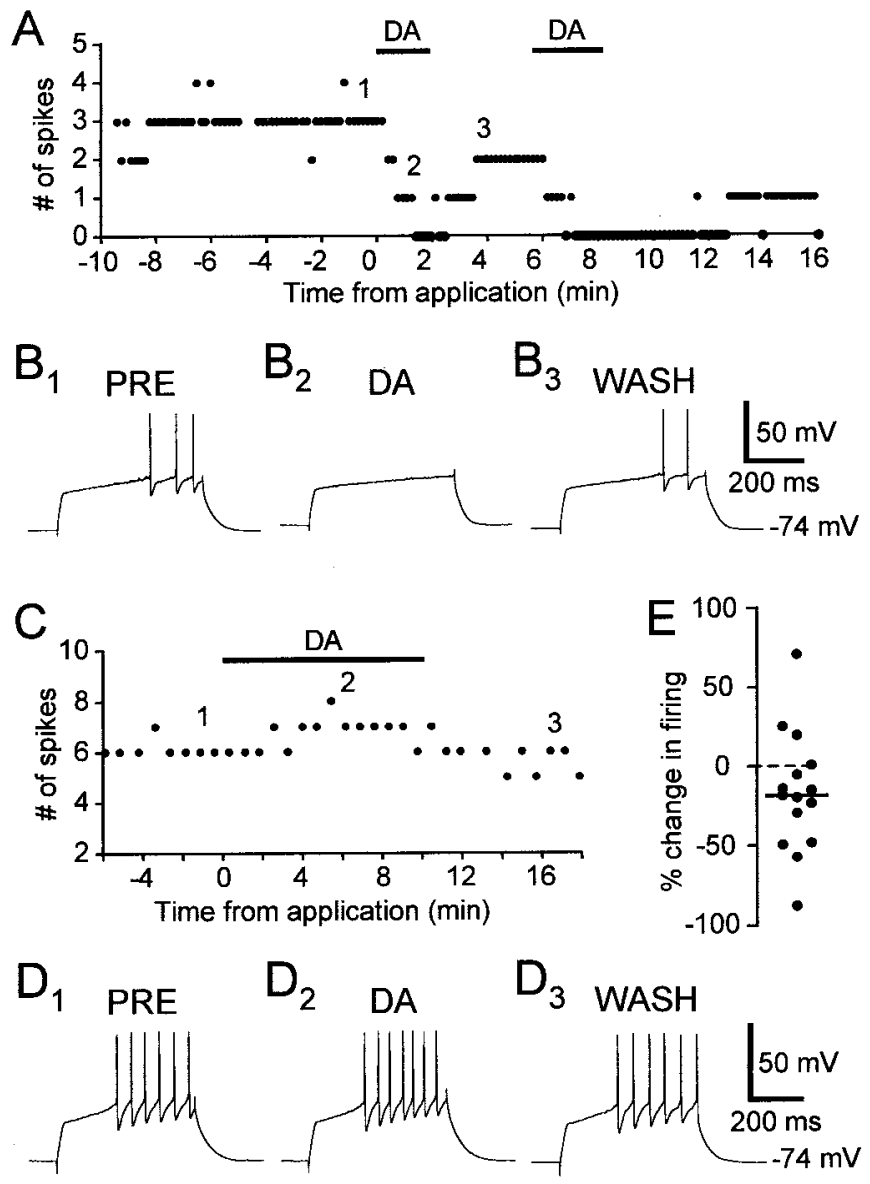

Figure 2. DA had opposite effects on two spiny neurons. $A$, DA $(40 \mu \mathrm{M})$ reversibly reduced evoked firing in a spiny neuron. DA was applied twice sequentially. The number of spikes in response to a current pulse $(+0.14$ nA) was plotted. $B_{1-3}$, Example traces from the experiment shown in $A$. The numbers shown in $A$ indicate the timing of each example trace. Resting membrane potential: $-74 \mathrm{mV}$. $C$, DA $(50 \mu \mathrm{M})$ increased evoked firing in a spiny neuron. $D_{1-3}$, Example traces from the experiment shown in $C$. Resting membrane potential: $-74 \mathrm{mV}$. E, Distribution of the effects of DA on excitability in spiny neurons, shown as percentage change of evoked firing $(n=15)$.

\section{The D2-like DA receptor agonist quinpirole reduces excitability in spiny neurons}

We next tested whether there are functional D2-like DA receptors in area X and LPO, whether activation of these receptors decreases spiking activity in spiny neurons, and if so, whether that could account for the inhibitory effect of DA. We found that the D2-like DA receptor agonist quinpirole $(5-10 \mu \mathrm{M})$ markedly reduced evoked firing in spiny neurons in area X and LPO (Fig. 6). Unlike the enhancement of excitability by D1 DA receptor activation, the reduction in evoked firing by quinpirole application is not voltage dependent (Fig. 7). In the 16 cells tested, the range of the percentage change in evoked firing was from -95 to $-14.6 \%$ with a mean of $-52.3 \%$ and SD of $26.0 \%$ (see Fig. 9). This effect was antagonized by the D2-like DA receptor antagonist sulpiride $(10 \mu \mathrm{M})$ (Figs. 8,9$)(n=4)$, suggesting that the effect of quinpirole was D2-like DA receptor specific.

Moreover, sulpiride completely blocked the inhibitory effect of DA. In the presence of sulpiride, DA failed to decrease evoked firing in all four cells tested. Instead, it slightly enhanced spike activity in these cells by $+13.8 \%$ on average (example traces not
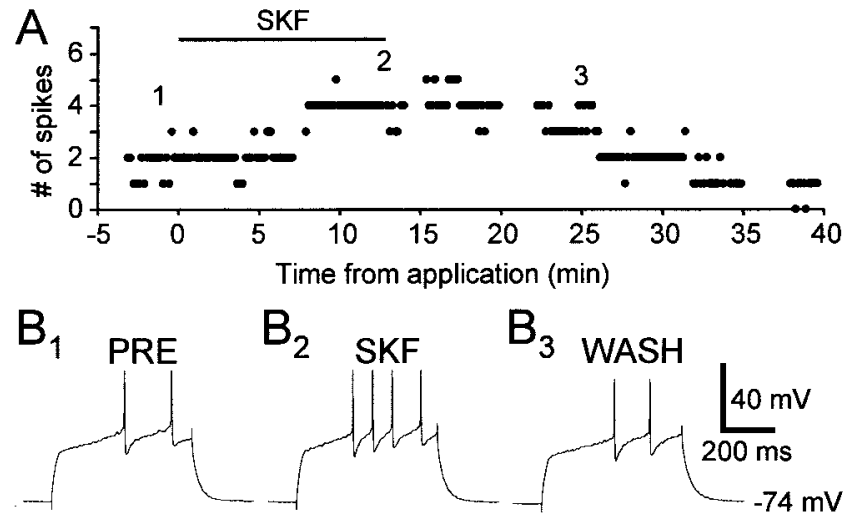

Figure 3. The D1-like DA receptor agonist SKF-38393 $(10 \mu \mathrm{M})$ reversibly enhanced excitability in a spiny neuron in area $\mathrm{X}$. $A$, The number of spikes evoked by suprathreshold current pulses $(+0.08 \mathrm{nA}) . B_{1-3}$, Example traces from the experiment shown in $A$. The numbers shown in $A$ indicate the timing of each example trace. Resting membrane potential: $-74 \mathrm{mV}$.

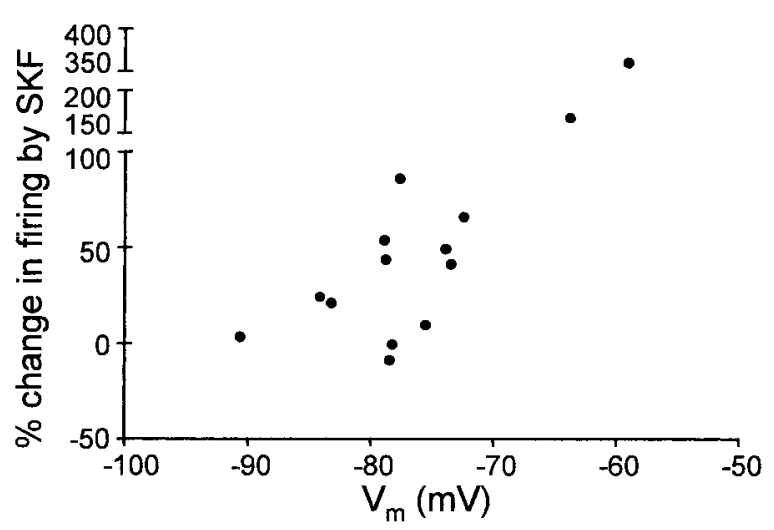

Figure 4. Voltage dependence of the effect of SKF-38393 $(n=14)$. The percentage change in firing was plotted as a function of the baseline membrane potential of each cell measured before current pulses.

shown; range, 4.8-25\%; SD, 9.6\%) (Fig. 9), suggesting that the inhibitory effect of DA was mediated by activation of D2-like DA receptors.

The data from experiments using various combinations of dopaminergic compounds are summarized in Figure 9. The effect of DA spans a wide range, with a bias toward negative values, and appears unimodal, without distinct clusters. In contrast, the D1like DA receptor agonist SKF-38393 and the D2-like DA receptor agonist quinpirole exert significant and opposite effects on the excitability (Wilcoxon signed rank test, two-tailed; $p=0.0012$ between baseline and SKF-38393 application; $p=0.0005$ between baseline and quinpirole application). Concurrent applications of SKF-38393 and SCH-23390 or quinpirole with sulpiride resulted in excitability not different from baseline (Wilcoxon signed rank test, two-tailed; $p=0.75$ for the SKF-38393-SCH23390 combination; $p=0.25$ for the quinpirole-sulpiride combination), consistent with the receptor specificity of the agonists. The effect of DA in the presence of sulpiride was significantly different from the effect of concurrent applications of quinpirole and sulpiride (Mann-Whitney test, two-tailed; $p=0.0286$ ), further supporting our hypothesis that DA actions on spiny neuron excitability are mediated by activation of both D1- and D2-like receptor types. Our preliminary data from Bengalese finches 
A
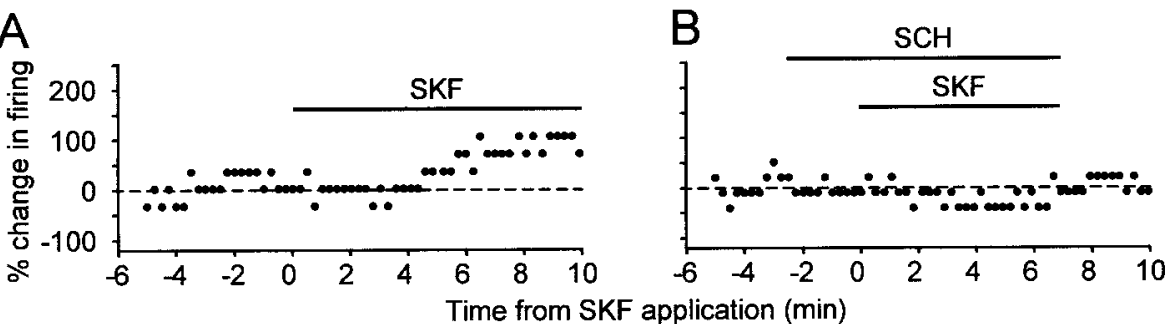

Figure 5. The D1-like DA receptor antagonist SCH-23390 blocked the excitatory effect of SKF38393 and DA. All data were collected from the same spiny neuron. $A$, SKF-38393 $(10 \mu \mathrm{M})$ enhanced excitability. $B, \quad \mathrm{SCH}-23390 \quad(20 \mu \mathrm{M})$ blocked the effect of SKF-38393 $(10 \mu \mathrm{M})$. C, DA $(50 \mu \mathrm{M})$ enhanced excitability. $D$, In the presence of SCH-23390 $(20 \mu \mathrm{M})$, DA $(50 \mu \mathrm{M})$ reduced evoked firing.
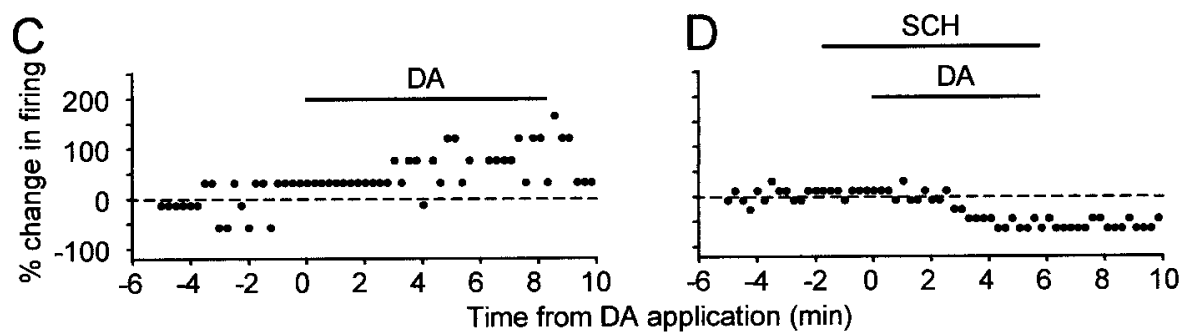

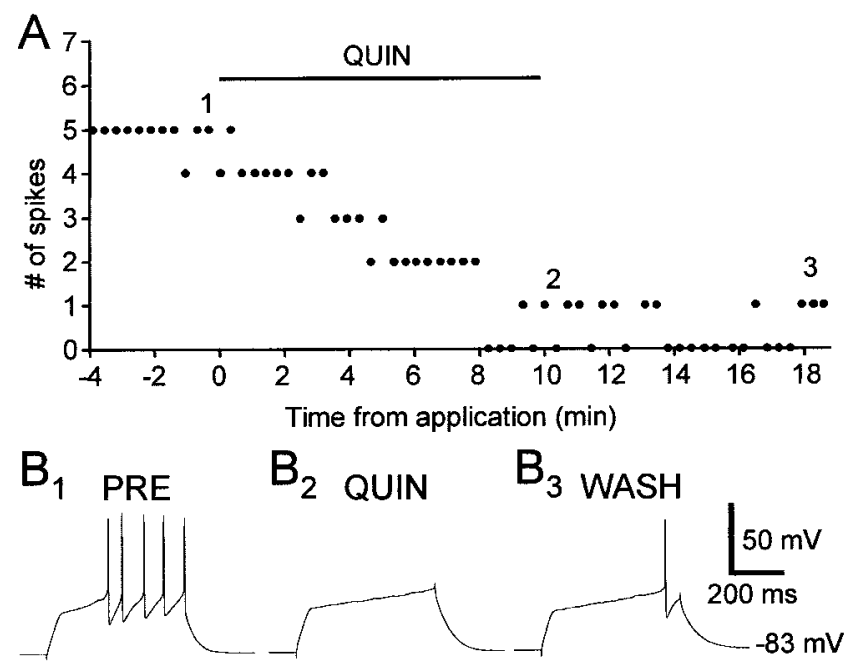

Figure 6. The D2-like DA receptor agonist quinpirole $(10 \mu \mathrm{M})$ significantly reduced evoked firing in a spiny neuron. $A$, The number of spikes evoked by suprathreshold current pulses $(+0.10 \mathrm{nA}) . B_{1-3}$, Example traces from the experiment shown in $A$. The numbers shown in $A$ indicate the exact timing of each example trace. Resting membrane potential: $-83 \mathrm{mV}$.

suggest that these effects are common in songbird species $(n=2$ for SKF-38393 application, 25 and 21.9\%; $n=1$ for quinpirole application, $-33.3 \% ; n=1$ for DA application, $-17.2 \%$ ). We also did not find any difference in their responses to DA and quinpirole between cells obtained with whole-cell and perforated-patch techniques, suggesting that the effects we observed are present in intact neurons as well.

\section{DA and its agonists modulate other intrinsic properties in spiny neurons: possible mechanisms underlying their effect on excitability}

To test whether DA directly influences excitability in spiny neurons in avian basal ganglia, we applied DA in the presence of a mixture of the $\mathrm{GABA}_{\mathrm{A}}$ receptor antagonist picrotoxin $(150 \mu \mathrm{M})$, the $\mathrm{GABA}_{\mathrm{B}}$ receptor antagonist CGP35348 (500 $\left.\mu \mathrm{M}\right)$, the AMPA/kainate glutamate receptor antagonist CNQX $(10 \mu \mathrm{M})$, the NMDA glutamate receptor antagonist D-APV $(50 \mu \mathrm{M})$, and the muscarinic cholinergic receptor antagonist atropine $(1 \mu \mathrm{M})$. DA reduced excitability in three cells tested, and this effect is not

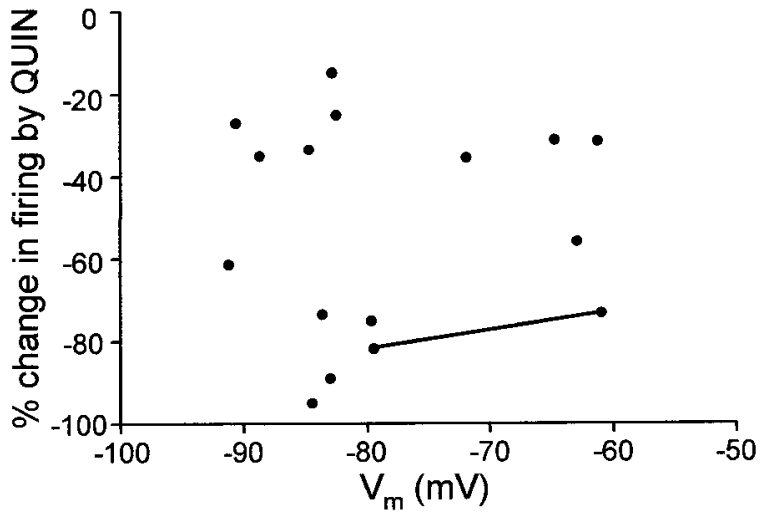

Figure 7. The effect of quinpirole is not voltage dependent $(n=16)$. The percentage change in firing is plotted as a function of the baseline membrane potential of each cell measured before current pulse injections. The data points connected by a line are from the same cell.

significantly different from that in the absence of the mixture of blockers (Mann-Whitney test, two-tailed; $p=0.11$ ), suggesting that DA affects excitability via direct actions on the intrinsic properties of spiny neurons.

As an initial attempt to elucidate the biophysical mechanisms underlying the effects of DA and its agonists, we examined whether other changes occurred in the intrinsic properties of spiny neurons (Table 1$)$. We found significant $(p<0.05)$ changes in the initial ramp slope and spike amplitude with applications of DA, SKF-38393, and quinpirole. The relationship between the percentage change in evoked firing and the change in initial ramp slope in response to quinpirole and SKF-38393 applications are shown in Figure 10, $A$ and $B$, respectively. Application of quinpirole also significantly prolongs the latency to the first spike, consistent with a reduction in the slow ramp (Fig. 10C). To examine further which properties underlie the effect of DA on excitability, the percentage change in each of these properties was correlated with the percentage change in evoked firing. This test revealed significant correlations between the percentage change in firing and the percentage change in initial ramp slope for DA, SKF-38393, and quinpirole applications (Spearman nonparametric correlation test, two-tailed; $p=0.0045,0.0061$, and 0.0002 , respectively). Also, the reduced firing induced by quinpirole was correlated with prolonged delay to the first spike (two-tailed; $p=$ 

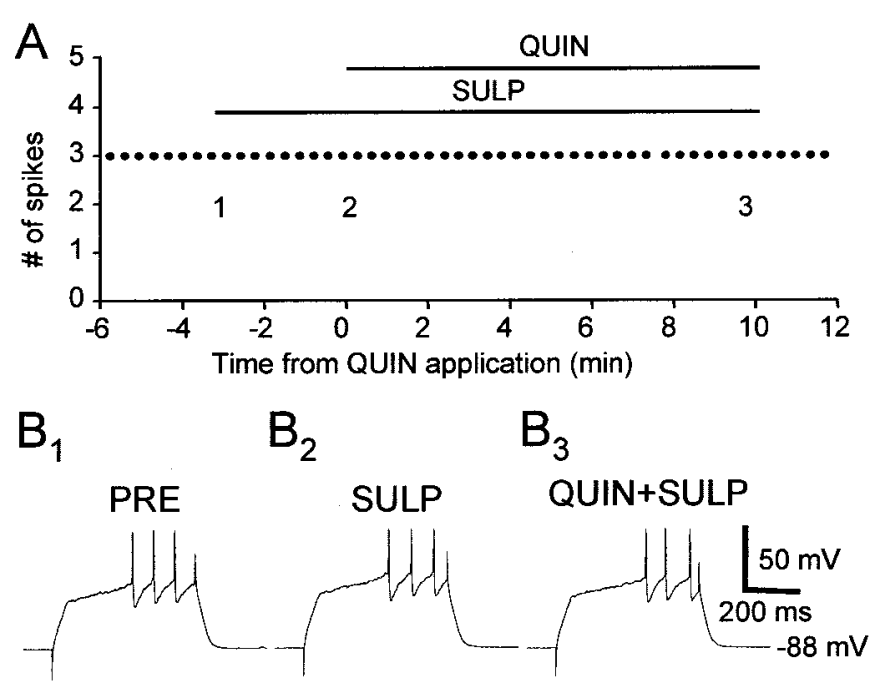

Figure 8. The D2-like DA receptor antagonist sulpiride $(10 \mu \mathrm{M})$ blocked the effect of quinpirole $(10 \mu \mathrm{M})$. $A$, the number of spikes evoked by suprathreshold current pulse injections $(+0.10 \mathrm{nA}) . B_{1-3}$, Example traces from the experiment shown in $A$. The numbers shown in $A$ indicate the timing of each example trace. Resting membrane potential: $-88 \mathrm{mV}$.

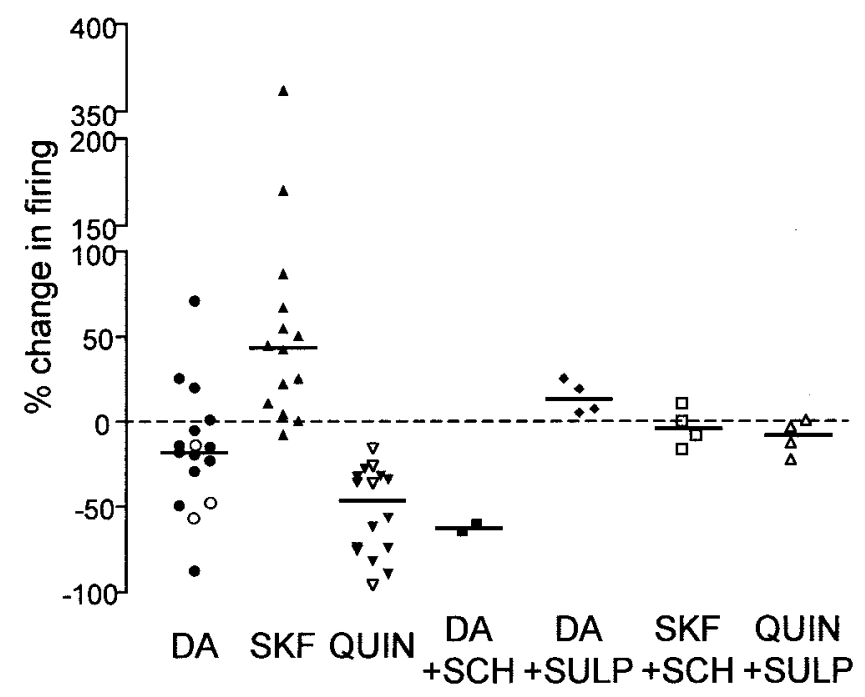

Figure 9. Distribution of the effects on cell excitability of DA $(n=15)$ (O, cells obtained with perforated-patch technique), SKF-38393 $(n=14)$, quinpirole $(n=16)(\triangle$, cells obtained with perforated-patch technique), DA in the presence of SCH-23390 $(n=2)$, DA in the presence of sulpiride $(n=4), \mathrm{SKF}-38393$ in the presence of SCH-23390 $(n=4)$, and quinpirole in the presence of sulpiride $(n=4)$. A horizontal line indicates the median value for each distribution. Dashed horizontal line indicates $0 \%$. The distribution of the effect of DA is identical to that shown in Figure $2 E$. For statistical analysis, see Results.

0.0002). These results suggest that DA and its agonists may modulate the conductance involved in the characteristic slow ramp of spiny neurons.

The slow ramp depolarization is greatly reduced by tetrodotoxin (TTX) application (Fig. 10D) $(n=12$; Wilcoxon signed rank test, two-tailed; $p=0.0005)$, suggesting that persistent $\mathrm{Na}^{+}$ current contributes to the ramp. In the presence of TTX, SKF38393 did not change the slope (Fig. 10B) $(n=5$, Wilcoxon signed rank test, two-tailed; $p=0.4375)$, whereas quinpirole further reduced the slope (Fig. $10 A, D)(n=7$; two-tailed; $p=$ $0.0313)$. These results suggest that D1-like DA receptor activation may enhance excitability by modulating persistent $\mathrm{Na}^{+}$conductance. Whether quinpirole application affects persistent $\mathrm{Na}^{+}$ conductance remains unknown, but clearly other pathways exist for its effect on the initial ramp depolarization in avian spiny neurons.

\section{DISCUSSION}

Our main finding is that DA receptor activation changes excitability in avian striatal spiny neurons. Activation of D1-like receptors enhances evoked firing in spiny neurons, whereas activation of D2-like receptors reduces it. Our data also indicate that some spiny neurons express both receptor types and suggest that colocalization in the entire population can account for the spectrum of DA actions (Fig. 11).

Interestingly, the effects of DA receptor activation that we observed in avian striatal spiny neuron excitability are mostly similar to those reported in mammals (Nicola et al., 2000). In both systems, D2-like DA receptor activation decreases evoked firing in spiny neurons (Hernandez-Lopez et al., 2000), whereas D1-like DA receptor activation enhances excitability in a voltagedependent manner (Hernandez-Lopez et al., 1997). These similarities, combined with those in the dopaminergic innervation pattern (for review, see Reiner et al., 1994) and the DA receptor localization (for review, see Durstewitz et al., 1999) in the avian and mammalian basal ganglia, suggest that the functions and physiology of the DA system are mostly conserved in amniotes.

There are differences, however, between our findings and those reported in the mammalian literature. The first difference is in the above-mentioned voltage dependence: SKF-38393 reduces excitability in rat spiny neurons at a hyperpolarized state (Calabresi et al., 1987; Hernandez-Lopez et al., 1997); we did not observe such a reduction in songbirds. The second difference is a lack of voltage dependence with D2-like DA receptor activation in birds, in contrast to the prediction in mammals, where voltagedependent $\mathrm{Ca}^{2+}$ conductance is modulated (Hernandez-Lopez et al., 2000). Another difference is that although DA reduces excitability via activation of D2-like DA receptors in birds, the similar inhibitory effect of DA is mediated by D1-like DA receptor activation in rats (Calabresi et al., 1987). In birds, activation of D1-like DA receptors mediates the enhancing effect of DA, which is mimicked by application of a D1-like DA receptor agonist and blocked by a D1-like DA receptor antagonist (Fig. 5).

One potential explanation for these differences is that the receptor specificity of the dopaminergic compounds used in this study is compromised in birds. We deem this possibility unlikely. Previous autoradiographic binding studies in the avian telencephalon with $\left[{ }^{3} \mathrm{H}\right] \mathrm{SCH}-23390,\left[{ }^{3} \mathrm{H}\right]$ spiperone, $\left[{ }^{3} \mathrm{H}\right] \mathrm{CV} 205-502$, and $\left[{ }^{3} \mathrm{H}\right]$ spiroperidol (for review, see Durstewitz et al., 1999) revealed DA receptor distributions in accord with dopaminergic innervation patterns obtained with tyrosine hydroxylase immunostaining (for review, see Reiner et al., 1994). There is no significant difference between avian and mammalian brains in the characteristics of DA receptor binding (Covelli et al., 1981; Casto and Ball, 1994; Demchyshyn et al., 1995). In addition, the sequences of avian D1- and D2-like DA receptors are highly homologous to those of their mammalian counterparts (Demchyshyn et al., 1995; Schnell et al., 1999), with the least similar regions, revealed by the BLAST sequence comparison program (Altschul et al., 1997), concentrated in the intracellular domains of the D1-like DA receptors. These results suggest that the extracellular domains of the DA receptors are mostly conserved in amniotes. The functional differences of dopaminergic compounds most likely reflect 
Table 1. Measurements of intrinsic properties of spiny neurons before and during drug application

\begin{tabular}{|c|c|c|c|c|c|c|}
\hline & PRE & $\begin{array}{l}\text { DA } \\
(n=15)\end{array}$ & PRE & $\begin{array}{l}\text { QUIN } \\
(n=16)\end{array}$ & PRE & $\begin{array}{l}\text { SKF } \\
(n=14)\end{array}$ \\
\hline$V_{\mathrm{m}}(\mathrm{mV})$ & $-81.6 \pm 5.64$ & $-81.3 \pm 5.98$ & $-77.8 \pm 10.2$ & $-77.4 \pm 10.2$ & $-76.4 \pm 7.95$ & $-75.9 \pm 8.22$ \\
\hline Initial ramp slope $(\mathrm{mV} / \mathrm{sec})$ & $75.1 \pm 32.0$ & $69.3 \pm 33.5$ & $77.2 \pm 37.2$ & $57.6 \pm 37.8$ & $61.8 \pm 21.0$ & $65.2 \pm 20.6$ \\
\hline Spike amplitude (mV) & $39.9 \pm 9.52$ & $37.2 \pm 9.19$ & $35.9 \pm 9.50$ & $33.0 \pm 11.2$ & $40.4 \pm 10.8$ & $37.4 \pm 10.4$ \\
\hline Spike threshold (mV) & $-34.3 \pm 5.95$ & $-32.8 \pm 6.24$ & $-37.7 \pm 7.23$ & $-37.7 \pm 8.68$ & $-38.9 \pm 5.76$ & $-37.4 \pm 7.21$ \\
\hline Latency to first spike (msec) & $208 \pm 68.0$ & $234 \pm 103$ & $175 \pm 73.4$ & $257 \pm 108$ & $207 \pm 125$ & $185 \pm 99.3$ \\
\hline AHP amplitude (mV) & $-12.6 \pm 4.34$ & $-12.4 \pm 4.58$ & $-11.7 \pm 4.20$ & $-11.6 \pm 4.81$ & $-8.15 \pm 7.69$ & $-7.40 \pm 6.01$ \\
\hline AHP duration (msec) & $15.9 \pm 5.18$ & $16.6 \pm 5.71$ & $22.0 \pm 11.9$ & $24.6 \pm 16.0$ & $18.6 \pm 11.8$ & $18.8 \pm 12.0$ \\
\hline$R_{\text {input }}(\mathrm{M} \Omega)$ & $233 \pm 130$ & $240 \pm 126$ & $267 \pm 165$ & $246 \pm 142$ & $246 \pm 103$ & $254 \pm 112$ \\
\hline Inward rectification ratio & $0.69 \pm 0.08$ & $0.72 \pm 0.10$ & $0.70 \pm 0.12$ & $0.73 \pm 0.11$ & $0.68 \pm 0.12$ & $0.69 \pm 0.08$ \\
\hline
\end{tabular}

Each measurement is expressed as mean \pm SD. PRE, Control; QUIN, quinpirole application; SKF, SKF-38393 application. Bold type indicates $p<0.05$; two-tailed Wilcoxon signed rank test.

Figure 10. The slope of the initial ramp is modulated by quinpirole, SKF-38393, and TTX. $A$, The percentage change in the slope of the initial ramp as a function of the percentage change in evoked firing induced by quinpirole $(n=15)$ (median value, $-28.6 \%$; the slope was not measured in one cell held at $-62 \mathrm{mV}$, which fired action potentials with very short latency). Solid line, Linear regression, $r^{2}=0.738$; dotted line, $95 \%$ confidence interval of the regression line. Horizontal dashed line indicates $0 \%$. Data points in shaded box were obtained in the presence of $1 \mu \mathrm{M}$ TTX ( $n=7$; median value $-12.5 \%)$. $B$, The percentage change in the slope of the initial ramp as a function of the percentage change in evoked firing induced by SKF$38393(n=14$; median value $3.3 \%)$. Solid line, Linear regression, $r^{2}=0.531$; dotted line, $95 \%$ confidence interval of the regression line. Note: the rightmost data point was included for all analyses except the linear regression. Horizontal dashed line indicates $0 \%$. Data points in shaded box were obtained in the presence of $1 \mu \mathrm{M}$ TTX $(n=5$; median value $-1.0 \%)$. $C$, Example traces from a spiny neuron. The baseline voltage response (thin line) had a steeper ramp before action
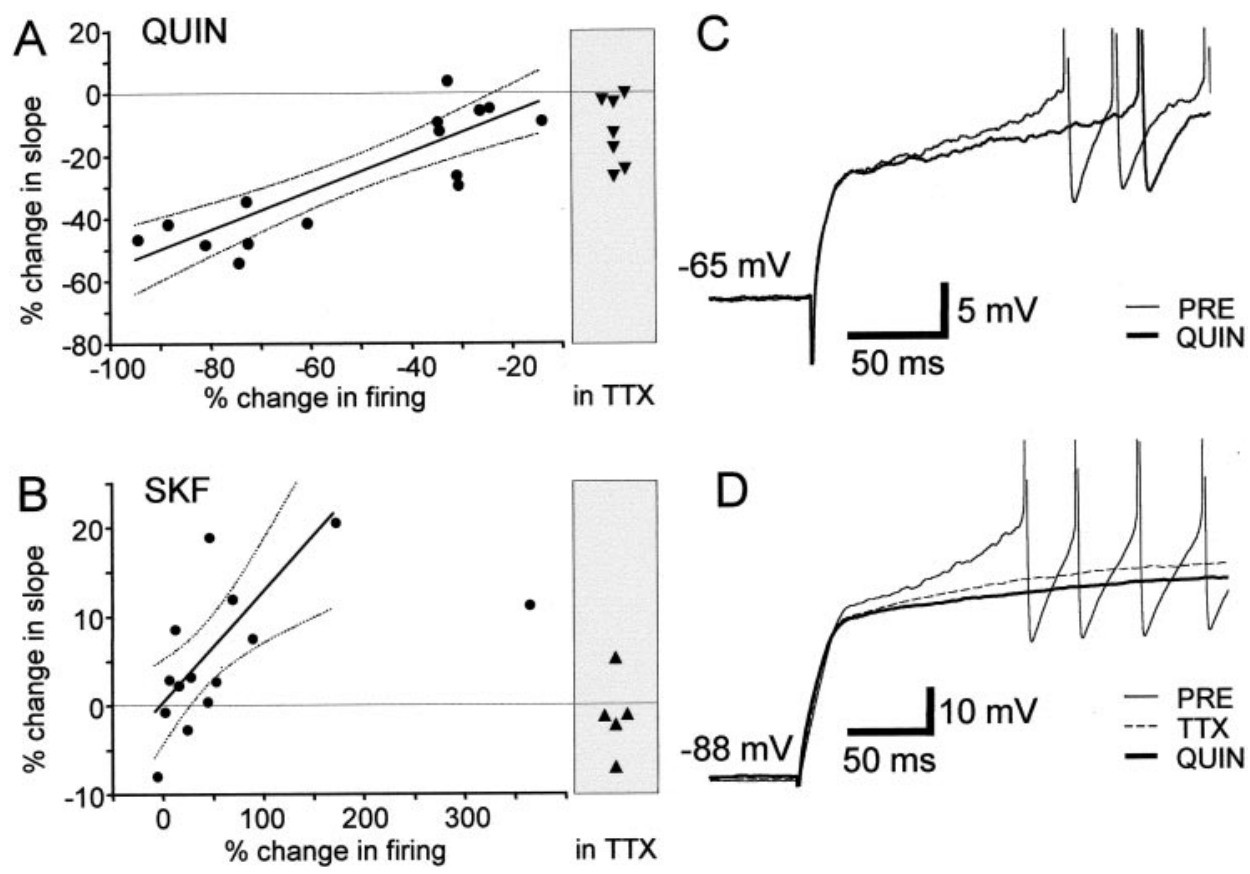
potential and an earlier onset of the first spike, compared with the response in the presence of quinpirole (thick line). Membrane potential: $-65 \mathrm{mV}$. $D$, TTX reduced the slope of the ramp but did not block the quinpirole-induced decrease. Example traces from another spiny neuron. Quinpirole (10 $\mu \mathrm{M})$ was applied in the presence of $1 \mu \mathrm{M}$ TTX. Membrane potential: $-88 \mathrm{mV}$. The control trace $(P R E)$ is shifted by $-1.9 \mathrm{mV}$ to facilitate comparison. The $T T X$ and QUIN traces shown are averages of three traces each.

differences in the intracellular signal cascades rather than different interactions between these compounds and the extracellular domains of DA receptors.

Although we did not specifically investigate the ionic basis of the effects of DA on spiny neurons, analysis of the voltage responses helped tease out potential mechanisms. In the avian and mammalian basal ganglia, spiny neurons show pronounced inward rectification mediated by a rapidly activating and noninactivating potassium conductance (Nisenbaum and Wilson, 1995; Farries and Perkel, 2002), which is modulated by D2-like DA receptor activation in mammals (Greif et al., 1995). The strong inward rectification could shape the voltage response to depolarizing current injections and thus affect the firing properties of spiny neurons. In addition to its possible role in excitability, this conductance contributes to the resting membrane potential and input resistance (Nisenbaum and Wilson, 1995; Farries and Perkel, 2000). We found that input resistance, resting membrane potential, and the ratio of inward rectification did not vary with cell excitability, suggesting that the inwardly rectifying potassium conductance is not involved in DA modulation of excitability. We also found no change in the spike threshold or in the amplitude or duration of fast AHPs, suggesting that DA and its agonists do not modulate the conductance directly responsible for spike generation. There was a reduction in the spike amplitude not associated with drug applications, most likely because of a rundown effect.

The most compelling candidate mechanism suggested by our analysis is modulation of the conductances mediating the slow ramp before action potentials in response to suprathreshold current injections (Fig. 10A-C). We found a strong correlation between the change in the slope of the initial slow ramp and the change in evoked firing induced by applications of DA and its agonists. In addition, when DA antagonists blocked the receptorspecific changes in evoked firing, the slope values during drug application were not significantly different from the baseline values (data not shown). These results suggest that DA could alter the firing activity in spiny neurons by modulating the currents 

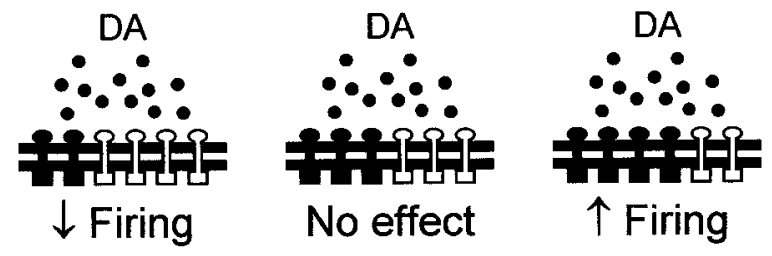

\section{D1 Receptor [็ D2 Receptor}

Figure 11. Proposed model to account for the spectrum of DA actions on excitability in avian spiny neurons in area X and LPO. The effect of DA on excitability in a given spiny neuron depends on its relative expression of D1- and D2-like DA receptors. DA reduces evoked firing in cells where D2-like DA receptors dominate and enhances firing in cells where D1-like DA receptors dominate. DA has no apparent effect in cells with no DA receptors at all (not shown) or in cells with equal influence by the two receptor types.

underlying the slow ramp depolarization. At least two types of current contribute to the slow ramp depolarization in mammalian and avian spiny neurons: a persistent noninactivating current, which is mediated possibly by both potassium and sodium conductances, and a slowly inactivating, 4-AP-sensitive A-type current, which is activated at depolarized membrane potentials (more than $-60 \mathrm{mV}$ ) (Calabresi et al., 1987; Nisenbaum and Wilson, 1995; Farries and Perkel, 2002). In mammals, DA reduces persistent $\mathrm{Na}^{+}$conductance (Cepeda et al., 1995). The underlying DA receptor types are unclear. In songbirds, TTX blocks the SKF-38393-induced increase in the slope of the ramp, suggesting that D1-like DA receptor activation may enhance excitability by augmenting persistent $\mathrm{Na}^{+}$current. Whether an increase in L-type $\mathrm{Ca}^{2+}$ conductance contributes to the SKF-38393-induced enhancement in excitability, similar to that described in mammals (Hernandez-Lopez et al., 1997), awaits further investigation. D2like DA receptor activation-induced reduction in the slope is not blocked by TTX. This does not exclude a possible involvement of the TTX-sensitive persistent $\mathrm{Na}^{+}$current but suggests that additional effectors also exist, such as the A-type $\mathrm{K}^{+}, \mathrm{Ca}^{2+}$, and TTX-insensitive slow $\mathrm{Na}^{+}$(Hoehn et al., 1993) conductances. It is possible that D2-like DA receptor activation modulates multiple conductances that operate at different voltage ranges. Interactions among these currents may explain the lack of apparent voltage dependence in quinpirole-induced decreases in excitability.

Because activation of different DA receptors results in different effects on excitability, the effect of DA itself on a given spiny neuron depends on specific subcellular localization of the DA receptors. In mammalian basal ganglia, it remains controversial whether DA receptors are segregated (Gerfen et al., 1990; Le Moine and Bloch, 1995) or colocalized (Surmeier et al., 1996; Aizman et al., 2000). Our data indicate that there is considerable colocalization of D1- and D2-like DA receptors in avian striatal spiny neurons. We showed that the DA-induced changes in excitability distribute in a continuum, instead of in two clusters. We observed that some cells have opposite changes in excitability in response to applications of DA and D1-like DA receptor agonist. In the cell with a D1-like DA receptor-mediated enhancement in excitability, we were able to uncover the D2-like DA receptormediated reduction by application of SCH-23390 (Fig. 5). These results indicate that functional D1- and D2-like DA receptors are coexpressed in at least some spiny neurons in the avian basal ganglia. However, there is also segregation to some extent. We encountered cells where DA reduced excitability and SKF-38393 had no effect $(n=2)$, suggesting that these cells expressed primarily D2-like DA receptors. We did not encounter cells that were affected by SKF-38393 but not by quinpirole, but they could exist. The distribution of the effects of DA, which is biased toward a reduction in excitability, suggests that the D2-like DA receptors exert a functional dominance in avian spiny neurons. This is consistent with the previous report that D2-like DA receptor density exceeds that of D1-like DA receptors in pigeon striatum, in contrast to the opposite D1/D2 receptor ratios found in the mammalian neostriatum (Richfield et al., 1987).

The differential expression patterns of DA receptors and the different physiological effects of their activation enable DA to modulate, in a complex manner, the output activity levels of the avian basal ganglia. Our results indicate that DA is capable of influencing the activity level in area $\mathrm{X}$ in adult songbirds by directly modulating cell excitability. Whether DA also exerts any effects on synaptic transmission in the avian basal ganglia is under investigation. A recent study in quail chicks suggested that D1like DA receptors might be essential for plasticity in the avian basal ganglia (Matsushima et al., 2001). Previous tyrosine hydroxylase staining studies demonstrated that the level of catecholaminergic (most likely dopaminergic) innervation changes during development in area X and LPO of zebra finch (Soha et al., 1996). These functional and temporal properties of the DAergic innervation in the avian basal ganglia and its established importance in mammals suggest that the DA system exerts fine control over complex avian behaviors such as song behavior. The naturally learned, stereotyped, and easily monitored singing behaviors in songbirds will likely help us gain insights into the role of DA in motor control and learning in vertebrates in general.

\section{REFERENCES}

Aizman O, Brismar H, Uhlen P, Zettergren E, Levey AI, Forssberg H, Greengard P, Aperia A (2000) Anatomical and physiological evidence for D1 and D2 dopamine receptor colocalization in neostriatal neurons. Nat Neurosci 3:226-230.

Altschul SF, Madden TL, Schäffer AA, Zhang J, Zhang Z, Miller W, Lipman DJ (1997) Gapped BLAST and PSI-BLAST: a new generation of protein database search programs. Nucleic Acids Res 25:3389-3402.

Blanton MG, Lo Turco JJ, Kriegstein AR (1989) Whole cell recording from neurons in slices of reptilian and mammalian cerebral cortex. J Neurosci Methods 30:203-210.

Bottjer SW (1993) The distribution of tyrosine-hydroxylase immunoreactivity in the brains of male and female zebra finches. J Neurobiol 24:51-69.

Bottjer SW, Johnson F (1997) Circuits, hormones, and learning: vocal behavior in songbirds. J Neurobiol 33:602-618.

Bottjer SW, Miesner EA, Arnold AP (1984) Forebrain lesions disrupt development but not maintenance of song in passerine birds. Science 224:901-903.

Brainard MS, Doupe AJ (2000) Interruption of a basal ganglia-forebrain circuit prevents plasticity of learned vocalizations. Nature 404:762-766.

Calabresi P, Mercuri N, Stanzione P, Stefani A, Bernardi G (1987) Intracellular studies on the dopamine-induced firing inhibition of neostriatal neurons in vitro: evidence for D1 receptor involvement. Neuroscience 20:757-771.

Casto JM, Ball GF (1994) Characterization and localization of D1 dopamine receptors in the sexually dimorphic vocal control nucleus, area $\mathrm{X}$, the basal ganglia of European starlings. J Neurobiol 25:767-780.

Cepeda C, Chandler SH, Shumate LW, Levine MS (1995) Persistent $\mathrm{Na}^{+}$conductance in medium-sized neostriatal neurons: characterization using infrared videomicroscopy and whole-cell patch-clamp recordings. J Neurophysiol 74:1343-1348.

Covelli V, Memo M, Spano PF, Trabucchi M (1981) Characterization of dopamine receptors in various species of invertebrates and vertebrates. Neuroscience 6:2077-2079.

Demchyshyn LL, Sugamori KS, Lee FJS, Hamadanizadeh SA, Niznik HB (1995) The dopamine D1D receptor. Cloning and characterization of three pharmacologically distinct D1-like receptors from Gallus domesticus. J Biol Chem 270:4005-4012.

Dietl MM, Palacios JM (1988) Neurotransmitter receptors in the avian brain. I. Dopamine receptors. Brain Res 439:354-359. 
Durstewitz D, Kröner S, Güntürkün O (1999) The dopaminergic innervation of the avian telencephalon. Prog Neurobiol 59:161-195.

Farries MA, Perkel DJ (2000) Electrophysiological properties of avian basal ganglia neurons recorded in vitro. J Neurophysiol 84:2502-2513.

Farries MA, Perkel DJ (2002) A telencephalic nucleus essential for song learning contains neurons with physiological characteristics of both striatum and globus pallidus. J Neurosci 22:3776-3787.

Gerfen CR, Engber TM, Mahan LC, Susel Z, Chase TN, Monsma FJ, Sibley DR (1990) D1 and D2 dopamine receptor-regulated gene expression of striatonigral and striatopallidal neurons. Science 250:1429-1432.

Graybiel AM, Aosaki T, Flaherty AW, Kimura M (1994) The basal ganglia and adaptive motor control. Science 265:1826-1831.

Greif GJ, Lin YJ, Liu JC, Freedman JE (1995) Dopamine-modulated potassium channels on rat striatal neurons: specific activation and cellular expression. J Neurosci 15:4533-4544.

Hernandez-Lopez S, Bargas J, Surmeier DJ, Reyes A, Galarraga E (1997) D1 receptor activation enhances evoked discharge in neostriatal medium spiny neurons by modulating an L-type $\mathrm{Ca}^{2+}$ conductance. J Neurosci 17:3334-3342.

Hernandez-Lopez S, Tkatch T, Perez-Garci E, Galarraga E, Bargas J, Hamm H, Surmeier DJ (2000) D2 dopamine receptors in striatal medium spiny neurons reduce L-type $\mathrm{Ca}^{2+}$ Currents and Excitability Via a Novel PLC $\beta 1-\mathrm{IP}_{3}-$ Calcineurin-signaling cascade. $\mathrm{J}$ Neurosci 20:8987-8995.

Hoehn K, Watson TWJ, MacVicar BA (1993) A novel tetrodotoxininsensitive, slow sodium current in striatal and hippocampal neurons. Neuron 10:543-552.

Le Moine C, Bloch B (1995) D1 and D2 dopamine receptor gene expression in the rat striatum: sensitive cRNA probes demonstrate prominent segregation of D1 and D2 mRNAs in distinct neuronal populations of the dorsal and ventral striatum. J Comp Neurol 355:418-426.

Lewis JW, Ryan SM, Arnold AP, Butcher LL (1981) Evidence for a catecholaminergic projection to area $X$ in the zebra finch. J Comp Neurol 196:347-354.

Luo M, Ding L, Perkel DJ (2001) An avian basal ganglia pathway essential for vocal learning forms a closed topographic loop. J Neurosci 21:6836-6845.

Matsushima T, Izawa EI, Yanagihara S (2001) D1-receptor dependent synaptic potentiation in the basal ganglia of quail chicks. NeuroReport 12:2831-2837.

McDougall SA, Zolman JF, Mattingly BA (1987) Effects of apomorphine and haloperidol on response suppression learning of young chicks. Behav Neurosci 101:254-263.

Missale C, Nash SR, Robinson SW, Jaber M, Caron MG (1998) Dopamine receptors: from structure to function. Physiol Rev 78:189-225.

Nicola SM, Surmeier DJ, Malenka RC (2000) Dopaminergic modulation of neuronal excitability in the striatum and nucleus accumbens. Annu Rev Neurosci 23:185-215.

Nisenbaum ES, Wilson CJ (1995) Potassium currents responsible for inward and outward rectification in rat neostriatal spiny projection neurons. J Neurosci 15:4449-4463.

Nisticò G, Stephenson JD (1979) Dopaminergic mechanisms and stereotyped behaviour in birds. Pharmacol Res Commun 11:555-570.

Reiner A, Medina L, Veenman CL (1998) Structural and functional evolution of the basal ganglia in vertebrates. Brain Res Rev 28:235-285.

Reiner A, Karle EJ, Anderson KD, Medina L (1994) Catecholaminergic perikarya and fibers in the avian nervous system. In: Phylogeny and development of catecholamine systems in the CNS of vertebrates (Smeets WJAJ, Reiner A, eds), pp 135-181. Cambridge, UK: Cambridge UP.

Rhee JS, Ebihara S, Akaike N (1994) Gramicidin perforated patchclamp technique reveals glycine-gated outward chloride current in dissociated nucleus solitarii neurons of the rat. J Neurophysiol 72:1103-1108.

Richfield EK, Young AB, Penney JB (1987) Comparative distribution of dopamine $\mathrm{D}-1$ and $\mathrm{D}-2$ receptors in the basal ganglia of turtles, pigeons, rats, cats, and monkeys. J Comp Neurol 262:446-463.

Sanberg PR, Mark RF (1983) The effect of striatal lesions in the chick on haloperidol-potentiated tonic immobility. Neuropharmacology 22:253-257.

Scharff C, Nottebohm F (1991) A comparative study of the behavioral deficits following lesions of various parts of the zebra finch song system: implications for vocal learning. J Neurosci 11:2896-2913.

Schnabel R, Braun K (1996) Development of dopamine receptors in the forebrain of the domestic chick in relation to auditory imprinting. An autoradiographic study. Brain Res 720:120-130.

Schnell SA, You S, Foster DN, El Halawani ME (1999) Molecular cloning and tissue distribution of an avian D2 dopamine receptor mRNA from the domestic turkey (Maleagris gallopavo). J Comp Neurol 407:543-554.

Schultz W (1998) Predictive reward signal of dopamine neurons. J Neurophysiol 80:1-27.

Soha JA, Shimizu T, Doupe AJ (1996) Development of the catecholaminergic innervation of the song system of the male zebra finch. J Neurobiol 29:473-489.

Sohrabji F, Nordeen EJ, Nordeen KW (1990) Selective impairment of song learning following lesions of a forebrain nucleus in the juvenile zebra finch. Behav Neural Biol 53:51-63.

Stewart MG, Kabai P, Harrison E, Steele RJ, Kossut M, Gierdalski M, Csillag A (1996) The involvement of dopamine in the striatum in passive avoidance training in the chick. Neuroscience 70:7-14

Surmeier DJ, Song WJ, Yan Z (1996) Coordinated expression of dopamine receptors in neostriatal medium spiny neurons. J Neurosci 16:6579-6591.

Vates GE, Nottebohm F (1995) Feedback circuitry within a songlearning pathway. Proc Natl Acad Sci USA 92:5139-5143

Yanai J, Silverman WF, Shamir D (1995) An avian model for the reversal of 6-hydroxydopamine induced rotating behavior by neural grafting. Neurosci Lett 187:153-156. 